\title{
The Impact of Memory Strategy Instruction on Learners' EFL Vocabulary Retention
}

\author{
Mohammad Reza Ghorbani \\ Bojnord University, Bognord, Iran \\ Email:mrg872@yahoo.com \\ Nushin Karami Riabi \\ Islamic Azad University, Garmsar Branch, Iran \\ Email: nu.karami@gmail.com
}

\begin{abstract}
The Depth of Processing Hypothesis (DPH) suggests that the more cognitively one is engaged in learning a word, the more likely it is to remember it later. This study was an attempt to test and substantiate this Hypothesis by assessing the impact of memory strategy instruction on learners' short-term and long-term vocabulary retention. True experimental design was employed to study two classes of 40 randomly selected intermediate learners as control and experimental groups. Both groups were exposed to the same vocabulary learning activities; however, only the experimental group received the treatment regarding memory strategies. A 35-item vocabulary test was developed by the researchers based on the instructed material (the "Intermediate Vocabulary" textbook by B. J. Thomas). The reliability of the test was estimated 0.72 through KR-21 formula. The results of the first and second independent samples t-test analysis from the immediate and delayed post-tests indicated that the experimental group had a better performance than the control group on the delayed post-test only. Thus, the findings confirm the long-term effectiveness of instruction through memory strategies and support the DPH.
\end{abstract}

Index Terms-memory strategies, EFL Learner, long-term retention, vocabulary instruction

\section{BACKGROUND}

In Iran English as a Foreign Language (EFL) is taught academically in class for a limited period of time each week with no immediate communicative purposes. Students are exposed to abundant words and grammatical rules. Language teachers have been teaching vocabulary as a core component of language proficiency by means of traditional methods such as flash cards, notebook with list of vocabulary, dictionaries, synonyms, antonyms etc. Learning words and how to use them is quite challenging and learners of English as a foreign language (EFL) cannot achieve their potential without an extensive vocabulary. One of their main problems with vocabulary learning is that it is here today, gone tomorrow.

According to Danesi (2003), in traditional language teaching only 4\% of learners' brain is activated. Many authors suggest that a deeper level of new word processing will ensure better retention. One of the most commonly accepted views of vocabulary learning is that teaching language learning strategies leads to better vocabulary retention. Language learning strategies are "strategies which contribute to the development of the language system which the learner constructs and affect learning directly" (Rubin, 1987, p. 22).

According to Nemati (2009) research into language learning strategies dates back to the1960s and researchers have had many publications on vocabulary learning since the 1990s. She argues that since learners forget much of what they learn, memory strategy instruction can result in long lasting knowledge without increasing study time. Based on the Depth of Processing Hypothesis (DPH), the more cognitively one is engaged in learning a word, the more likely it is to remember it later. Depth in this hypothesis refers to greater degree of semantic involvement. Remembering information depends not only on attention and rehearsal but also on the levels of processing. The implication is that the depth of processing is more important than the recency and length of exposure in remembering new words. Remembering the old information depends upon the nature of the cognitive process that is applied to process that information. So, teachers need to teach their students how to process new words deeply for better retention (Craik, 2002; Craik \& Tulving, 1975; Craik \& Lockhart, 1972).

According to Nation (2001), vocabulary learning strategies as subcategories of language learning strategies lead learners to take responsibility for their own learning. Language learning strategies refer to whatever learners employ to make learning easier, faster, and more enjoyable. They help learners to proceed with language learning tasks by facilitating comprehension, internalization, storage, retrieval, and use of the target language. By becoming aware of their own learning process, learners gradually feel independent and confident (Oxford 1990; O’Malley \& Chamot, 1990; Rubin, 1987). Therefore, strategy instruction is a crucial part of any foreign or second language teaching program (Schmitt, 1997). 
Oxford (1990, p.1) defines language learning strategies as, "steps taken by students to enhance their own leaning, they are tools for active, self-directed involvement, which is essential for developing communicative competence" and distinguishes between direct strategies dealing with the language itself and indirect strategies concerned with management of learning. Direct strategies are divided into three sub-strategies: memory strategies for storing and retrieving information, cognitive strategies for language comprehension and application, and compensation strategies for language application despite gaps in knowledge. Therefore, direct strategies are helpful to the students due to the fact that they help learners store and retrieve information, assist them in producing language even when there is a gap in knowledge, and also help them understand and use the new language. Indirect strategies comprise meta-cognitive strategies for planning, monitoring comprehension, organizing, and evaluating learning, affective strategies for dealing with the task in a positive way, and social strategies for involving and cooperating with other people to get input and practice.

According to Oxford (1990), memory strategies, traditionally known as mnemonics, have been around since ancient times. They involve linking the word with some previously learned knowledge and their goal is organization and consolidation. Her memory sub-strategies (acronym, grouping, and imagery), which help learners store and retrieve information, were taught to examine their impact on the short-term and long-term vocabulary retention. In this study, short-term retention (STR) refers to the learners' performance on the exam immediately after the treatment but longterm retention (LTR) refers to the learners' performance on the exam two weeks after the treatment. Using acronyms (forming a real or nonsense word from the first letters of a list of words) will not help learners to understand the information but to memorize and remember it better. Grouping words belonging to the same category together also make them easy to remember. Categorizing and breaking down a lot of language materials into small meaningful subgroups and then parts in order to make the information simple to remember by reducing the number of trivial elements. Using imagery refers to linking a list of things to concepts in memory by picturing them together or separately. Employing meaningful pictures either in the mind or in an actual drawing is believed to lead to better memorization and retention.

Since vocabulary is still a fundamental challenge and the current focal point of teaching and research (Wei, 2007), this study was conducted to test DPH and possibly alleviate the problem by using three memory strategies in vocabulary instruction. Memory strategies were used as mnemonics by learners to make mental linkages that would allow new words to enter, remain, and retrieved for communication in long-term memory. Some researchers suggest that effective instruction requires a deeper level of processing of new words. However, more empirical evidence is needed to support this hypothesis. According to O'Malley and Chamot, (1990) and Oxford (1990), these strategies are more effective than memorization and parrot-like repetition techniques which need shallow processing. Vocabulary learning is a memory problem (Yongqi, 2003) and one of the major ways of researching vocabulary teaching techniques is doing experimental comparisons of vocabulary learning activities (Hulstijn and Laufer, 2001). In this study, the impact of teaching memory strategies on storing (short-term retention evaluated by immediate post-test) and retaining (long-term retention evaluated by delayed post-test) new words was investigated using two groups of intermediate female subjects.

In order to assess whether or not memory strategy instruction enhances short-term and long-term vocabulary retention of the subjects participating in the experimental group of this study, the following question was formulated.

Does teaching EFL vocabulary through memory strategies impact EFL learners' short-term and long-term vocabulary retention?

To answer the research question, the following null hypotheses were formulated.

1. Teaching EFL vocabulary through memory strategies has no significant impact on learners' short-term vocabulary retention.

2. Teaching EFL vocabulary through memory strategies has no significant impact on learners' long-term vocabulary retention.

\section{METHODOLOGY}

\section{A. Research Design}

This study followed a true experimental design in which the control group received no treatment, the subjects were randomly selected and assigned to two groups, and a pre-test was administered to capture the initial differences between the groups. The following diagram summarizes the design. The dotted line represents equivalent groups. In this diagram GA and GB stand for experimental and control groups respectively. T1 stands for the test before applying the treatment. $\mathrm{T} 2$ and $\mathrm{T} 3$ stand for the tests after the treatment and X stands for treatment.

\begin{tabular}{|c|c|c|c|}
\hline GA & $\mathrm{T} 1$ & $\mathrm{X}$ & $\mathrm{T} 2$ \\
\hline GB & $\mathrm{T} 1$ & & $\mathrm{~T} 2$ \\
\hline
\end{tabular}

\section{B. Subjects and Instruments}

Forty Iranian intermediate EFL learners participated in this study implemented at Kaneye Zaban which is an English institute in Bojnord located in the north east of the country. The participants were 40 Iranian intermediate EFL learners. All of them were adult female students selected based on a placement pre-test. Those who get 37 to 42 scores out of 70 
in Interchange placement test are called intermediate English learners. Forty out of 70 participants were eligible to attend the vocabulary class. They were randomly assigned to two groups. A coin was tossed to choose the experimental and control groups.

Although the pre-existing Interchange placement test (pre-test) was standard, its reliability was estimated 0.88 using the following formula:

$$
k r 21=\left(\frac{k}{k-1}\right)\left(1-\frac{\bar{X}(k-\bar{X})}{k \sigma^{2}}\right)=\left(\frac{70}{70-1}\right)\left(1-\frac{35.97(70-35.97)}{70 * 11.92^{2}}\right)=0.8869
$$

The vocabulary textbook "Intermediate Vocabulary" by B.J. Thomas was taught to both groups. In the control group, vocabulary was presented through different modes such as explanation, examples, synonyms, antonyms, etc. In the experimental group, the subjects were familiarized with the concept of memory strategies and their applications, too.

A 35-item multiple-choice vocabulary post-test was developed by the researchers. The items were designed based on the input from the above mention book. Before piloting phase, five English lecturers were asked to analyze the items for content and face validity. Then the test was piloted on the students who took the same course previous term. the reliability of the test was estimated 0.72 through KR-21 formula.

$$
k r 21=\left(\frac{k}{k-1}\right)\left(1-\frac{\bar{X}(k-\bar{X})}{k \sigma^{2}}\right)=\left(\frac{35}{35-1}\right)\left(1-\frac{27.58(35-27.58)}{35 * 4.445^{2}}\right)=0.72478
$$

\section{Procedure}

This study was implemented in four phases: pre-test, treatment, immediate post-test, and delayed post-test. The independent variable was the impact of teaching three types of memory strategies: imagery, grouping, and acronyms. And the dependent variable was the learners' short- and long-term EFL vocabulary retention.

The allocated time for teaching in both groups was 15 one hour sessions. Both classes were held at the same time in the afternoon. Vocabulary instruction in the control group included pronouncing words loudly, writing them on the board, explaining their parts of speech, defining or elaborating their meanings via synonyms and antonyms, using them in meaningful sentences, giving the Persian equivalents of abstract words to clarify their meanings, etc.

As to the experimental group, in addition to applying the techniques in the control group, the researchers made students aware of memory strategies which served as the independent variable. The subjects got acquainted with the concept of strategy through a handout including the definitions of three kinds of memory strategies (imagery, acronyms, and grouping) and examples to clarify them. For each kind of strategy 3 vocabulary items were given along with the instructions. The first 20 units of the intermediate vocabulary book were taught. The syllabus of each session`s teaching and the pictures needed for teaching concrete words had already been prepared. The researchers knew which words could be classified into groups and which ones were appropriate for making acronyms.

Immediately after the treatment, the first post-test was administered to measure the learners' short-term vocabulary retention. The same post-test with some changes in its arrangement was administered to the same subjects as the second post-test two weeks later to measure the learners' long-term vocabulary retention. According to Yongqi (2003, p. 12), "Delayed recall after 2 weeks under experimental conditions is normally referred to as long-term retention".

\section{Statistical Analysis and Results}

Before analyzing the data, a few preliminary steps were taken to ensure the validity and reliability of the results. To answer the research question, the raw scores taken from the post-tests were submitted to the computer software Statistical Package of Social Sciences (SPSS version 15), using t-test. Paired-samples t-test was used to see whether there was a statistically significant difference in the mean scores for post-test 1 (immediate post-test) and post-test 2 (delayed post-test) of the same group. Independent samples t-test was conducted to compare the possible differences between the means of the experimental and control groups based on the gain scores from the post-tests. The research question and the corresponding hypotheses in this study are as follows:

Does teaching EFL vocabulary through memory strategies impact EFL learners' short-term and long-term vocabulary retention?

1. Teaching EFL vocabulary through memory strategies has no significant impact on learners' short-term vocabulary retention.

2. Teaching EFL vocabulary through memory strategies has no significant impact on learners' long-term vocabulary retention.

The following tables indicate the summary of t-tests.

TABLE 1

THE INDEPENDENT SAMPLES T-TEST FOR THE EXPERIMENTAL AND CONTROL GROUPS (POST-TEST 1)

\begin{tabular}{|l|l|l|l|l|l|l|}
\hline Group & N & Mean & Std Dev & df & t & Sig. \\
\hline Experimental Control & 2020 & 16.98 & 1.69 & 38 & .50 & 0.61 \\
& & 16.65 & 2.44 & & & \\
\hline
\end{tabular}


An independent samples t-test was conducted to compare the scores of the experimental and control groups immediately after the treatment (post-test 1). As indicated in Table 1, there is no significant difference between the experimental group $(M=16.98, S D=1.69)$ and the control group $[M=16.65, S D=2.44 ; t(38)=0.50, p .>.05]$. This result suggests that the first null hypothesis (teaching EFL vocabulary through memory strategies has no significant impact on learners' short-term vocabulary retention) fails to be rejected.

TABLE 2.

THE INDEPENDENT SAMPLES T-TEST FOR THE EXPERIMENTAL AND CONTROL GROUPS (POST-TEST 2)

\begin{tabular}{|l|l|l|l|l|l|l|}
\hline Group & N & Mean & Std Dev & df & t & Sig. \\
\hline Experimental Control & 2020 & 16.97 & 1.64 & 38 & 3.39 & $0.002 *$ \\
& & 14.56 & 2.72 & & & \\
\hline
\end{tabular}

The second independent samples t-test was conducted to compare the scores of the experimental and control groups two weeks after the treatment (post-test 2). As indicated in Table 2, there is a significant difference between the gain scores for the experimental group $(M=16.97, S D=1.64)$ and the gain scores for the control group $(M=14.56, S D=$ $2.72 ; t(38)=3.39, p<.05)$. This final result shows that the mean increment of the experimental group two weeks after the treatment is more than the control group. That is, the participants who received memory strategy instruction learned significantly more vocabulary than others. Since there is a significant difference between the means of the two groups, the null hypothesis (teaching EFL vocabulary through memory strategies has no significant impact on learners' longterm vocabulary retention) is rejected. Therefore, the DPH is supported.

TABLE 3.

THE PAIRED SAMPLES T-TEST FOR THE EXPERIMENTAL GROUP (POST-TEST $1 \&$ 2)

THE PAIRED SAMPLES T-TEST FOR THE EXPERIMENTAL GROUP (POST-TEST 1 \& 2)
\begin{tabular}{|l|l|l|l|l|l|l|}
\hline Experimental Group & N & Mean & Std Dev & df & t & Sig. \\
\hline Post-test 1 & 20 & 16.98 & 1.69 & 19 & 0.063 & 0.951 \\
Post-test 2 & 20 & 16.97 & 1.64 & & & \\
\hline
\end{tabular}

Table 3 shows that there is no significant difference between the means of the two means in post-test 1 and 2 of the experimental group. This result suggests that the experimental group subjects performed the same in the immediate and delayed post-tests.

TABLE 4.

THE PAIRED SAMPLES T-TEST FOR THE CONTROL GROUP (POST-TEST $1 \&$ 2)

\begin{tabular}{|l|l|l|l|l|l|l|}
\hline Control Group & N & Mean & Std Dev & df & t & Sig. \\
\hline Post-test 1 & 20 & 16.65 & 2.44 & 19 & 9.549 & $0.000 *$ \\
Post-test 2 & 20 & 14.56 & 2.72 & & & \\
\hline
\end{tabular}

Table 4 shows that there is a significant difference between the two means in post-test 1 and 2 of the control group. This result suggests that the control group subjects performed better in the immediate post-test in comparison to the delayed post-test.

\section{DISCUSSION AND CONCLUSION}

The result of the first independent samples t-test analysis from the immediate post-test indicated that the experimental group who received memory strategy instruction had almost the same performance as the control group who did not receive it. This means that the impact of memory strategy instruction on short-term retention is not significant. However, the result of the second independent samples t-test analysis from the delayed post-test administration indicated that the experimental group had a better performance than the control group. This suggests that memory strategy instruction is useful for the long-term vocabulary retention. The results of the paired-samples ttests also shows that there is a significant difference between the two means in post-test 1 and 2 of the control group only. This result suggests that the control group subjects performed better in the immediate post-test in comparison to the delayed post-test. Since teaching memory strategies seems to have facilitated the process of long-term EFL vocabulary retention, its application can be suggested to reinforce the EFL vocabulary learning.

The findings of this study confirm the long-term effectiveness of instruction through memory strategies and support the DPH. The findings are in line with Nemati (2009), Schmitt and Schmitt 1995), and Craik and Tulving (1972). However, they are different from Marefat and Shirazi's (2003) findings in which learners who received memory strategy instruction performed better in short-term retention test than long-term retention test. This discrepancy may be due to the inappropriate combinations and use of strategies in terms of time, place, and method (Yongqi, 2003; LessardClouston, 1997 as cited in Marefat and Shirazi, 2003). The result of this study can be justified in keeping with Craik and Tulving' (1972) perspective that in the short-term, information is stored easily, but in the long-term, it is recalled only if it is deeply and meaningfully processed. However, due to the limitations of this study, the results should be interpreted cautiously. In fact, further research in this regard is in order. The implications from the findings of this study suggest 
that if memory strategies are incorporated into the curriculum and instructed in EFL classes, long-term retention of new EFL words will be facilitated.

\section{REFERENCES}

[1] Craik, F. I. M. (2002). Levels of processing: Past, present... and future? Memory, 10, 305-318.

[2] Craik, F. \& Lockhart, R. (1972). Levels of processing: A framework for memory research. Journal of Verbal Language and Verbal Behavior, 11, 671-684.

[3] Craik, F. \& Tulving, E. (1975). Depth of processing and retention of words in episodic memory. Journal of Experimental Psychology, 103(3), 268-294.

[4] Danesi, M. (2003). Second language teaching a view from the right side of the brain. Boston: Kluwer Academic Publishers.

[5] Hulstijn, J., \& Laufer, B., (2001). Some empirical evidence for the involvement load hypothesis in vocabulary acquisition. Language Learning, 51(3), 539-558.

[6] Marefat, H. \& Shirazi M. A. (2003). The impact of teaching direct learning strategies on the retention of vocabulary by EFL learners. The reading matrix 3(2), 47-62.

[7] Nation, I. S. P. (2001). Learning vocabulary in another language. Cambridge: Cambridge University Press.

[8] Nemati, A. (2009). Memory vocabulary learning strategies and long-term retention. International Journal of Vocational and Technical Education, 1(2), 014-024.

[9] O’Malley, J. M. \& Chamot, A. U. (1990). Learning strategies in second language acquisition. Cambridge: Cambridge University Press.

[10] Oxford, R. L. (1990). Language learning strategies: what every teacher should know. Boston: Heinle and Heinle Publishers.

[11] Rubin, J. (1987). Learner strategies: Theoretical assumptions, research history and typology. In A. Wenden and J. Rubin (Eds.), Learner strategies and language learning, (pp.15-29). Englewood Cliffs, N J: Prentice Hall.

[12] Schmitt, N. (1997). Vocabulary learning strategies. In N. Schmitt \& M. McCarthy (Eds.), Vocabulary: Description, Acquisition and Pedagogy (pp.199-227). Cambridge: Cambridge University Press.

[13] Schmitt N, Schmitt D (1995). Vocabulary notebooks: Theoretical understanding and practical suggestions. ELT Journal, 49(2), 133-142.

[14] Wei, M. (2007). An examination of vocabulary learning of college-level learners of English in China. Asian EFL Journal, 9(2), 93-114.

[15] Yongqi Gu, P. (2003). Vocabulary learning in a second language: person, task, context and strategies. TESL-E J, 7(2), 1-28

Mohammad Reza Ghorbani has worked as an EFL teacher and researcher in Iran, Japan, and Malaysia since 1990. He has published two books on educational issues and six articles in specialized international journals. He has also presented 10 papers in international conferences. His interests are English Teaching, Learning, Testing, and Evaluation.

Nushin Karami Riabi holds an M.A. in Teaching English as a Foreign Language (TEFL). She has been an English teacher for 12 years and has run a language institute since 2008. 